\title{
Gaseous Scanning Electron Microscope (GSEM): Applications and Improvement
}

\author{
Lahcen Khouchaf \\ Université Lille - Nord de France, Ecole des Mines de Douai, Douai,
}

France

\section{Introduction}

The imaging and the microanalysis of hydrated and insulating materials using electron beam probe methods (Conventional SEM, Auger Electron Microscopy,...) are very limited by the necessity to keep the sample under high vacuum and the presence of the charge effect. In this case the sample must be coated except when the experiment is performed at very low energy in order to avoid the charge phenomenon. Studies of vegetable and biological samples are almost impossible without degradation. In Conventional SEM (Pressure $=10^{-5}$ mbar in the specimen chamber) image quality and microanalysis results are strongly related to the size of the electron beam, the accelerating voltage and the nature of the sample. A large description of different aspects on SEM/EDS exists in the literature (Newbury et al, 1986; Goldstein et al, 1992).

In order to overcome the high vacuum in the specimen chamber different types of microscopes with the possibility to introduce different gases inside the sample chamber are now available (Danilatos, 1980, 2009, Carlton, 1997, Wight, 2001). Depending on the pressure value in the specimen chamber different names are given in the literature such as ESEM: Environmental Scanning Electron Microscope, LVSEM: Low Vacuum Scanning Electron Microscope, HPSEM: High Pressure Scanning Electron Microscope, VPSEM: Variable Pressure Scanning Electron Microscope, CPSEM: Controlled pressure Scanning Electron Microscope and depending on the maximum pressure attainable in the specimen chamber (Danilatos 1988, Khouchaf \& Vertraete, 2002, 2004; Khouchaf et al., 2006, 2007, 2010, 2011; Kadoun et al, 2003; Gilpin, 1994; Carlton, 1997; Doehne, 1997; Newbury 2002; Gauvin, 1999; Bolon, 1991; Wight, 2001). But all these microscopes differ from CSEM by the capability to introduce the gas as an environment unlike High vacuum in CSEM and the use of gaseous detection system such as Gaseous Secondary Electron Detector (GSED). Indeed, all these microscopes may be called Gaseous Scanning Electron Microscope (GSEM).

Unlike CSEM, with GSEM image quality and microanalysis results are strongly related to the size of the electron beam, the accelerating voltage, the nature of the sample and depend on the pressure in the chamber and the kind of gas used. GSEM showed the enormous use in several fields using materials. The electron beam scattering tends to decrease the resolution. Different correction methods were developed (Bilde-Sorensen et al, 1996; Doehne, 1996-1997; Le Berre et al, 1997; Gauvin et al, 1999) but weren't satisfactory for many reasons such as the time and the difficulty of implementation. 
In this chapter different applications using GSEM will be given in the first part. In the second part an introduction of some physical phenomena related to the scattering of the primary electron beam with the gas and their consequence on the image quality and on the microanalysis results is given. The focus here is to present the potential, the limitation and some way to optimize the use of GSEM.

\section{Applications of ESEM}

GSEM allows imaging and analysis of many types of materials without any preparation with the presence of a gaseous environment. Gas atoms or molecules interact with the primary electron beam and produce positive ions. The presence of the positive ions allows neutralization the negative charge on the surface of the insulating sample. Gas serves also for detection (Danilatos, 1988).

Different types of gases may be introduced such as: $\mathrm{N}_{2}, \mathrm{O}_{2}, \mathrm{Ar}, \mathrm{He}, \mathrm{H}_{2} \mathrm{O}$...... As an illustration, we give two examples. By introduction of gases, vacuum incompatible materials, and dynamic surface modification may be studied. At pressures in excess of 500 $\mathrm{Pa}$, water can be condensed in situ enabling characterization of hydrated materials.

In this study, the experiments were performed in environmental 'wet' mode using an Environmental Scanning Electron Microscope (ESEM) «ElectroScan 2020 » equipped with EDS Microanalysis system "Oxford Linkisis ». The electron source is a tungsten filament. The energy of the electron beam used was $20 \mathrm{kV}$ with an emission current of $49 \mu \mathrm{A}$. The condenser is also fixed at $43 \%$ value and the diameter of the projection aperture is $50 \mu \mathrm{m}$. Secondary electrons were detected using a long gaseous secondary electron detector (GESD)at a working distance of $19 \mathrm{~mm}$ is used in order to reduce the skirt beam phenomena. The chamber pressure is varied by introducing gas.

The sample is embedded in epoxy resin and polished.

For the estimation of the unscattered fraction and the skirt radius an ESEM electron flight simulator software was used (Electron Flight Simulation Software, version 3.1-E).

\subsection{Observation of vegetable}

Plant material is insulating and has a fragile structure. Its observation using an electron beam is a delicate operation. Its structure is degraded under the electron beam. Some plants contain Stomata (or epidermis) the structures deposited on the outer leaf skin layer. They consist of two cells, called guard cells that surround a tiny pore called a stoma. Stomata allow communication between the internal and external environments of the plant.

Figure 1a shows an image of a plant after the coating operation in order to neutralize the negative charges. The image is obtained at $20 \mathrm{kV}$ and high vacuum using the Gaseous Secondary Electron Detector (GSED) detector. This specimen is formed by stomata which are tiny openings or pores, found mostly on the underside of a plant leaf and used for gas exchange. The image below shows an elongated and irregular structure.

The same observation is made without coating under a gaseous environment of water vapor (Fig.2b). In this case, the morphological aspect and the structure of the plant are very different compared to the image in Fig. 1a. The sample kept its structure. We can observe 
the stomata in their natural state. In order to study mechanism of exchange in the plant, it is necessary to keep the sample in its natural state. This is possible by using GSEM. It is interesting to underline that despite the scattering phenomena, the image kept its quality. That will be explained below.

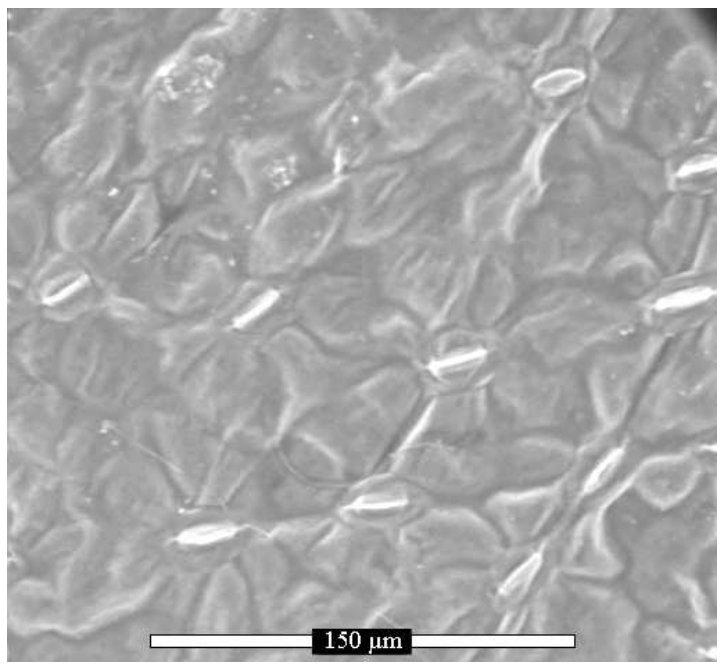

Fig. 1a. ESEM micrographs of a plant before the coating process.

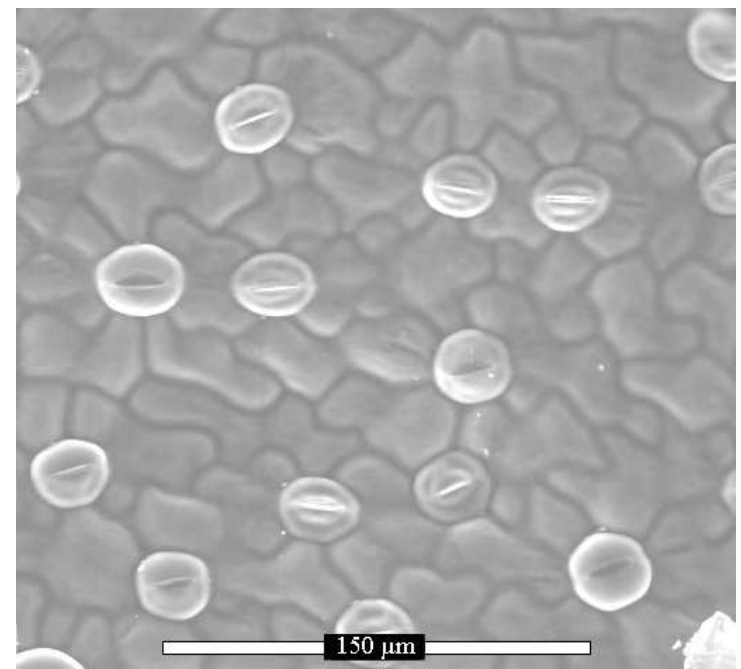

Fig. 1b. ESEM micrographs of a plant before the coating process.

\subsection{Detection of calcium potassium inside $\mathrm{SiO}_{2}$ Framework}

Figure 2 shows an example of a flint aggregate subjected to attack by Alkali-Silica Reaction (ASR). ASR is a physicochemical process which takes place during the degradation of 
concrete. Observation of the ASR effects using Scanning Electron Microscope (SEM) is important because the attack of the aggregate is heterogeneous on the microscopic scale. When using CSEM, sample preparation prior to imaging is required, which may lead to an alteration of the true surface morphology or even the creation of artifacts.

The use of GSEM overcomes these problems and gives direct imaging of the samples in their natural state. The image in Fig. 2 shows the presence of different degraded zones (1 to 8$)$ affected by chemical reaction. These zones have different micronic sizes and under the given conditions, the effect of the beam skirt is not the same. If the volume of the generation of Xrays is lower than the size of the zone then the effect of the skirt may be neglected. If the volume of the generation of $X$-rays is higher than the size of the zone then the effect of the skirt may be taken into account.

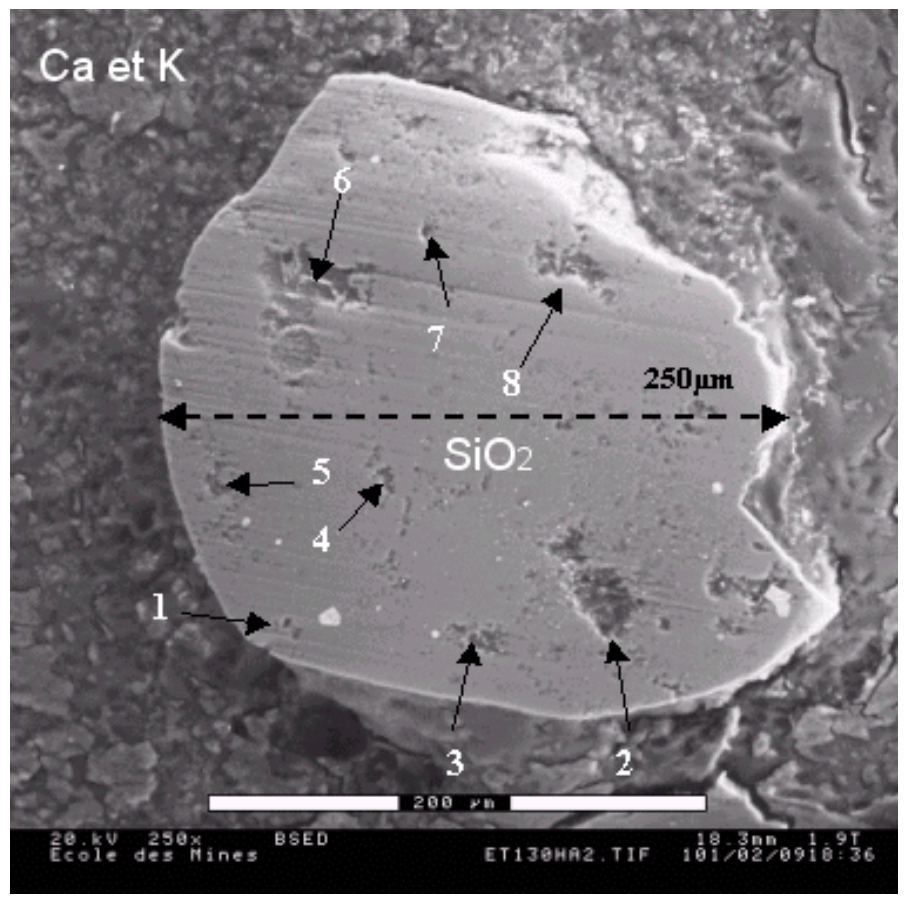

Fig. 2. ESEM micrographs of flint aggregate after reaction at (GSED, $\mathrm{P}=532 \mathrm{~Pa}$ ).

The images below (Figures 3) show the effect of calcium cations during the degradation of concrete. Figure 3a presents flint aggregate after 30 hours of reaction with the presence of calcium and potassium and figure $3 \mathrm{~b}$ without calcium. With the presence of calcium, it is interesting to note that the reaction has not finished particularly in the center of the aggregate (Fig. 3a).

However, when the calcium is removed, the grain is fragmented to small grain clearly separated by showing that the mechanism is different when calcium is present (Fig. 3b). Despite a high pressure (532 Pa) and high accelerating voltage $20 \mathrm{kV}$, again the resolution of the image is not bad. 

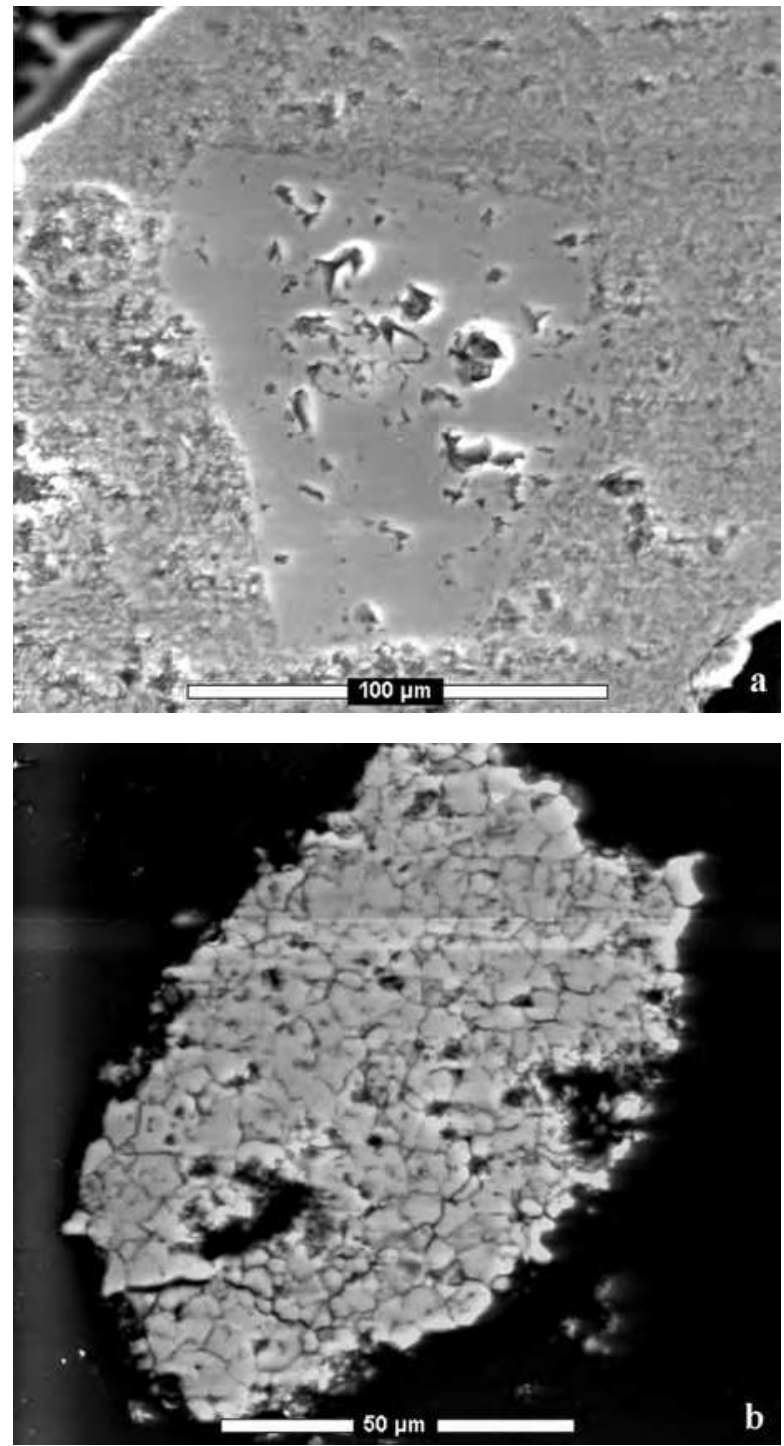

Fig. 3. ESEM micrographs of (a) flint aggregate after reaction at (GSED, $P=532 \mathrm{~Pa}$ ) with the presence of calcium, (b) flint aggregate after reaction (GSED, $\mathrm{P}=545.3 \mathrm{~Pa}$ ) without calcium.

\section{Description of the beam skirt}

Experiments above were performed with insulating materials without any preparation and without the coating procedure by introducing a gaseous environment into the specimen chamber. A part of primary electron beam interacts with the atoms or molecules of the gas.

The average collision number with particle gas per electron is given by the equation below: 


$$
\mathrm{m}=\sigma_{\mathrm{t}} \times \mathrm{n} \times \mathrm{L}
$$

Where

$\sigma_{\mathrm{t}}$ : scattering cross section is specific to each gas molecule

$\mathrm{n}$ : gas particle number/volume

L: Working distance (distance between the final aperture PLA1 and the surface of the sample see Figure 4). The Gas Path Length GPL is introduced and corresponds to the distance that electrons have to travel through the gas to reach the sample. $m$ may be expressed as below (Danilatos, 1988):

$$
m=\frac{\sigma_{T} \cdot L \cdot P}{k \cdot T}
$$

where $\sigma_{\mathrm{T}}$ is the total cross section of the gas, $\mathrm{L}$ the gas path length, $\mathrm{P}$ the gas pressure, $\mathrm{k}$ the Boltzmann constant and $\mathrm{T}$ the temperature.

Using the number $\mathrm{m}$ it is possible to define three different scattering regimes corresponding to:

Minimal scattering: $\mathrm{m}<0.05$

Partial scattering: $0.05<\mathrm{m}<3$

Plural scattering: $\mathrm{m}>3$

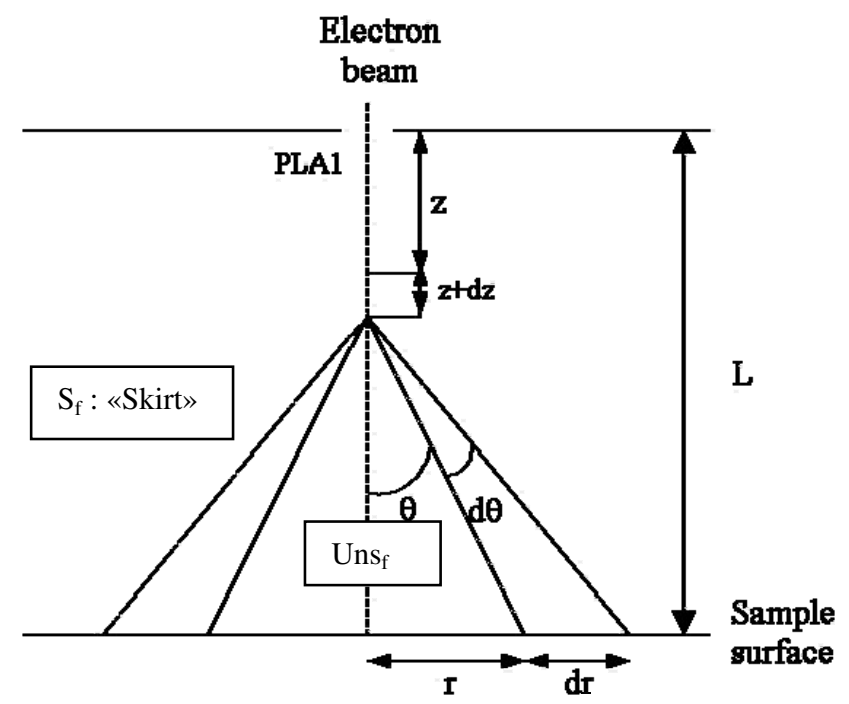

Fig. 4. An electron after PLA1 aperture of the ESEM, moves along the axis of PLA1, undergoes a collision at a distance between $z$ and $z+d z$ in an angle of $\theta+d \theta$; it is then scattered and arrives at the surface of the sample in an annulus between $r$ and $r+d r$.

After interaction between electron and gas, the primary electron beam is divided into two parts (Fig. 4) called "scattered fraction: $S_{f}$ " which corresponds to the elastic scattering by the gas atoms or molecules and a second part called "unscattered fraction: Unsf". The 
"unscattered fraction" of the electron beam can be written by the equation below when a simple mode of scattering is considered (Danilatos, 1988):

$$
\mathrm{Uns}_{\mathrm{f}}=\exp \left(-\frac{\mathrm{P} \times \mathrm{L} \times \sigma_{\mathrm{t}}}{\mathrm{k} \times \mathrm{T}}\right)
$$

P: Pressure in the specimen chamber

L: Working distance (WD, distance between the final aperture PLA1 (Fig. 1) and the surface of the sample). In this study the Gas Path Length GPL is introduced and corresponds to the distance that electrons have to travel through the gas to reach the sample.

$\sigma_{\mathrm{t}}$ : total scattering cross section is specific to each gas molecule

$\mathrm{k}$ : Boltzman constant

$\mathrm{T}$ : Temperature in Kelvin.

Elastic scattering leads to the enlargement of the primary electron beam to form a skirt producing the generation of X-rays which are not representative of the zone of interest for X-ray microanalysis. Different correction methods have been developed in order to take into account the contribution of the skirt (Bilde-Sorensen et al, 1996; Doehne, 1996-1997; Le Berre et al, 1997; Gauvin et al, 1999). Up to now these methods have not been successful. Danilatos, 1988 ) introduced the radius rs which represents the radius containing $90 \%$ of the incident beam) as below:

$$
r_{s}=\frac{364 \cdot Z}{E} \cdot\left(\frac{P}{T}\right)^{1 / 2} \cdot \mathrm{GPL}^{3 / 2}
$$

where $r_{s}$ is the skirt radius, $\mathrm{Z}$ the gas atomic number, $\mathrm{E}$ the incident beam energy, $\mathrm{P}$ the pressure, $\mathrm{T}$ the temperature and GPL the gas path length.

Considering the condition used in $\$ 2.2$, the simulations of the electron beam scattering were performed using the Electron Flight Simulator software (Figure 5a). In this case the unscattered fraction is about $85.7 \%$ with a rs of $26 \mu \mathrm{m}$. Worst case X-ray Gen radius means the approximate region where $\mathrm{X}$-ray signals will be generated and given just as indication. Based on our previous sudy using helium gas (Khouchaf et al, 2004, 2007, 2011), the same simulation under helium gas (Fig1.b) leads to $\mathrm{Uns}_{\mathrm{f}}$ of $97.6 \%$, $\mathrm{rs}<1 \mu \mathrm{m}$ showing a good improvement of the conditions with a gas having a low average atomic number.

Some authors (John F. Mansfield) have suggested that quantitative analysis is possible with ESEM (with water vapour as the standard gas) only under very restrictive conditions such as : short working distances between $6 \mathrm{~mm}$ and $7.2 \mathrm{~mm}$, gas path length between $1.2 \mathrm{~mm}$ and $2.2 \mathrm{~mm}$ in the 70 to $350 \mathrm{~Pa}$ range at high accelerating voltage of $30 \mathrm{kV}$. From these conditions it is easy to notice that the values of working distance, gas path length and pressure must be very low when the accelerating voltage decreases. Using conditions close to that given by Mansfield we perform a simulation by means of Electron Flight Simulator (Fig. 6a and 6b).

At $\mathrm{P}=70 \mathrm{~Pa}$ and GPL=1mm, $\mathrm{Uns}_{\mathrm{f}}$ and $\mathrm{r}_{\mathrm{s}}$ are close to $95.5 \%$ and $<1 \mu \mathrm{m}$ respectively. When the pressure increases to $350 \mathrm{~Pa}$ and GPL to $2 \mathrm{~mm}$ (Fig. 6b), $\mathrm{Uns}_{\mathrm{f}}$ decreases to $93.5 \%$ and $\mathrm{r}_{\mathrm{s}}$ increases to $2 \mu \mathrm{m}$.

Parameters suggested by Mansfield consider a high accelerating voltage of $30 \mathrm{kV}$ which is conform with excitation of heavy or metallic elements and which we can study by using 
CSEM. In addition, high voltage leads to large volume of interaction and a degradation of the resolution by generation of unwanted x-rays. More applications in GSEM require a low accelerating voltage which is possible by recent microscope with a FEG gun.

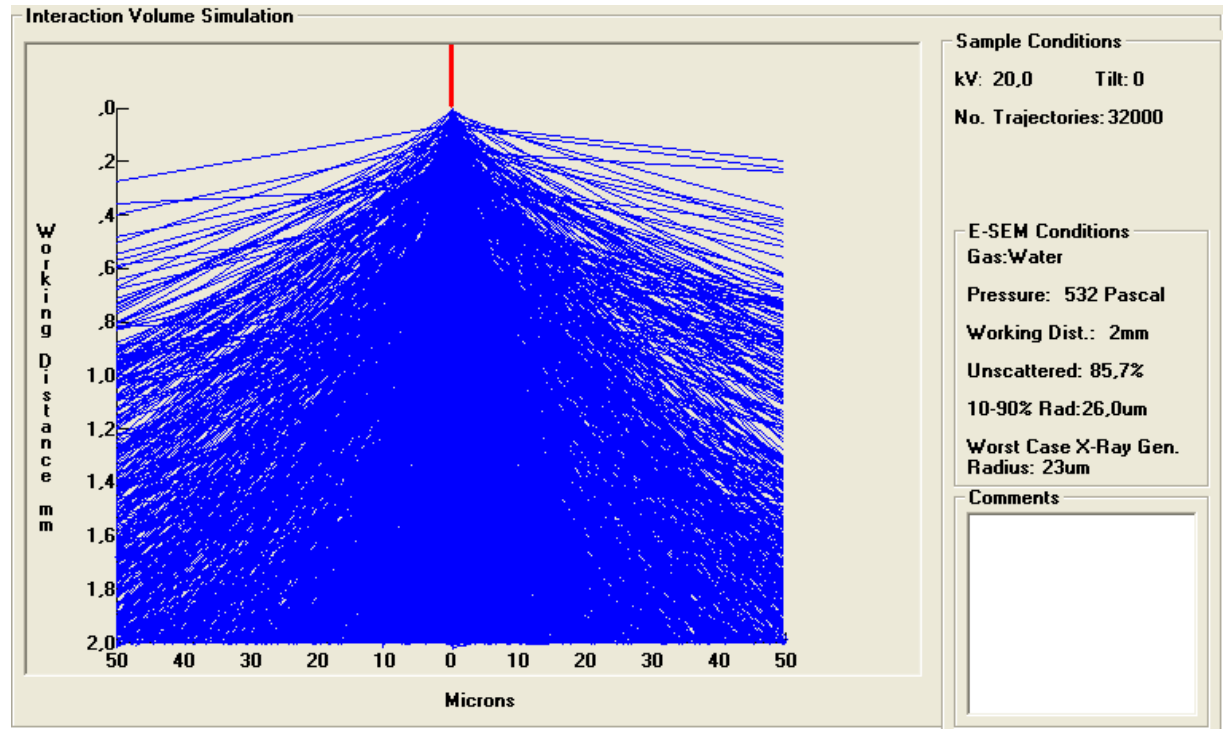

Fig. 5a. Monte Carlo simulation using Electron Flight Simulator of the electron beam scattering under water vapor, $\mathrm{V}=20 \mathrm{kV}, \mathrm{P}=532 \mathrm{~Pa}, \mathrm{GPL}=2 \mathrm{~mm}$.

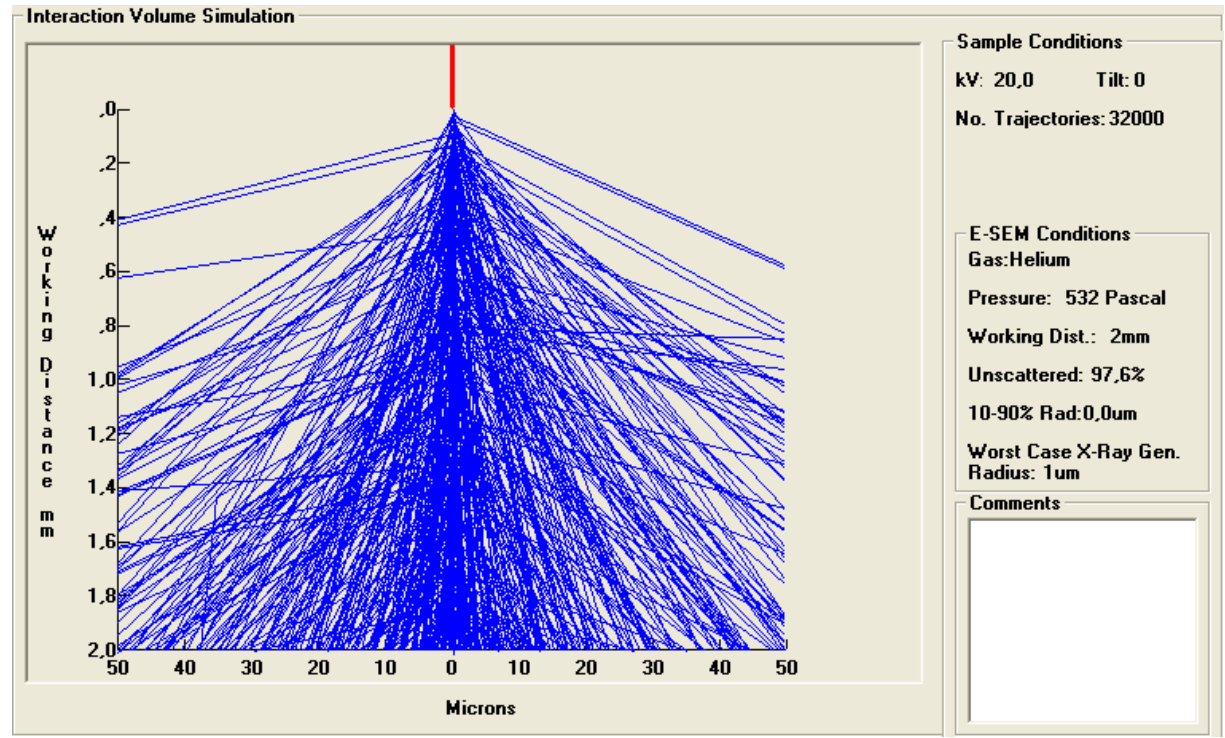

Fig. 5b. Monte Carlo simulation using Electron Flight Simulator of the electron beam scattering under helium, $\mathrm{V}=20 \mathrm{kV}, \mathrm{P}=532 \mathrm{~Pa}, \mathrm{GPL}=2 \mathrm{~mm}$. 


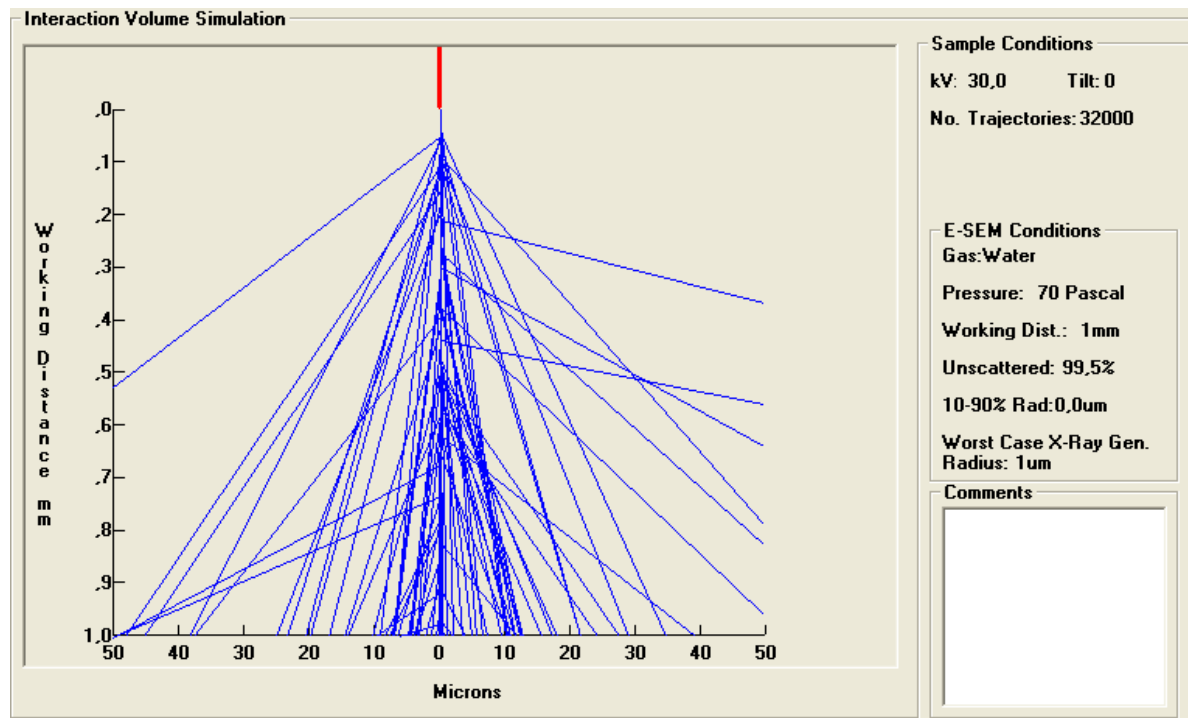

Fig. 6a. Monte Carlo simulation using Electron Flight Simulator of the electron beam scattering under water vapor, $\mathrm{V}=30 \mathrm{kV}, \mathrm{P}=70 \mathrm{~Pa}, \mathrm{GPL}=1 \mathrm{~mm}$.

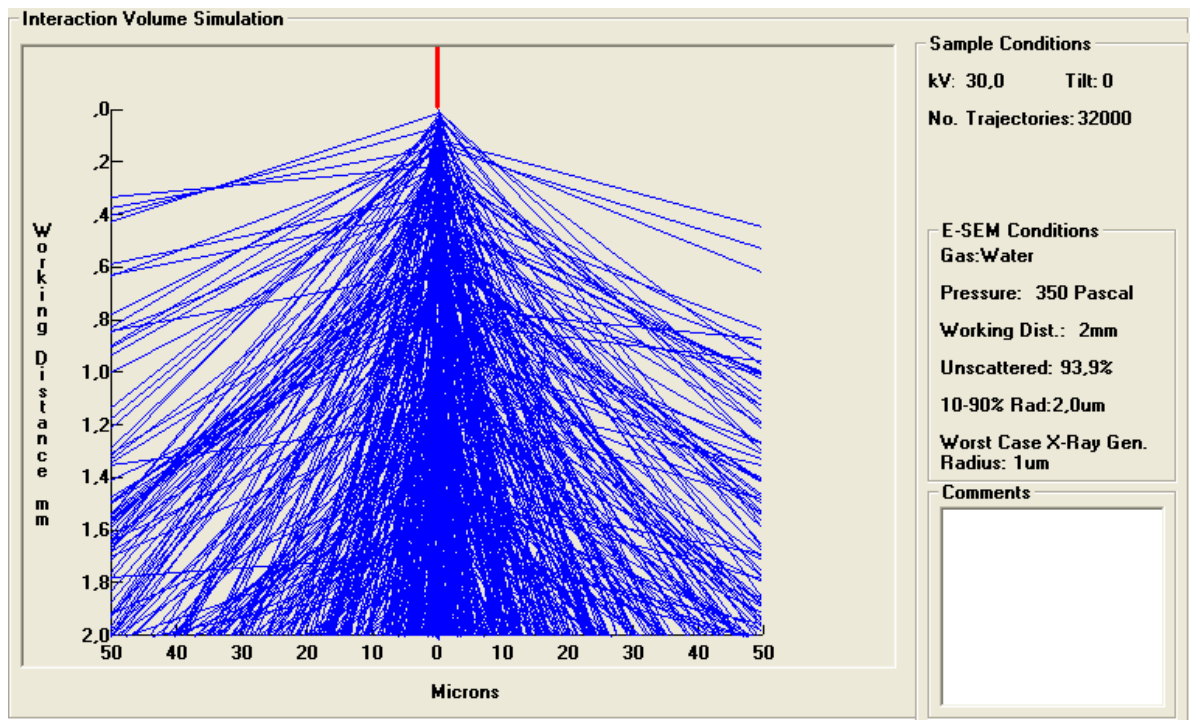

Fig. 6b. Monte Carlo simulation using Electron Flight Simulator of the electron beam scattering under water vapor, $\mathrm{V}=30 \mathrm{kV}, \mathrm{P}=350 \mathrm{~Pa}, \mathrm{GPL}=2 \mathrm{~mm}$.

Let us consider the conditions above at low accelerating voltage of $5 \mathrm{kV}$ under water vapor (Fig7a and $7 \mathrm{~b}$ ). At $\mathrm{P}=70 \mathrm{~Pa}$ and $\mathrm{GPL}=1 \mathrm{~mm}, \mathrm{Uns}_{\mathrm{f}}$ and $\mathrm{r}_{\mathrm{s}}$ are close to $93.2 \%$ and $12 \mu \mathrm{m}$ respectively, but at $\mathrm{P}=350 \mathrm{~Pa}$ and $\mathrm{GPL}=2 \mathrm{~mm}, \mathrm{Uns}_{\mathrm{f}}$ and $\mathrm{r}_{\mathrm{s}}$ are close to $47 \%$ and $109.3 \mu \mathrm{m}$ respectively. It is easy to conclude that the quality of the results will be affected. 


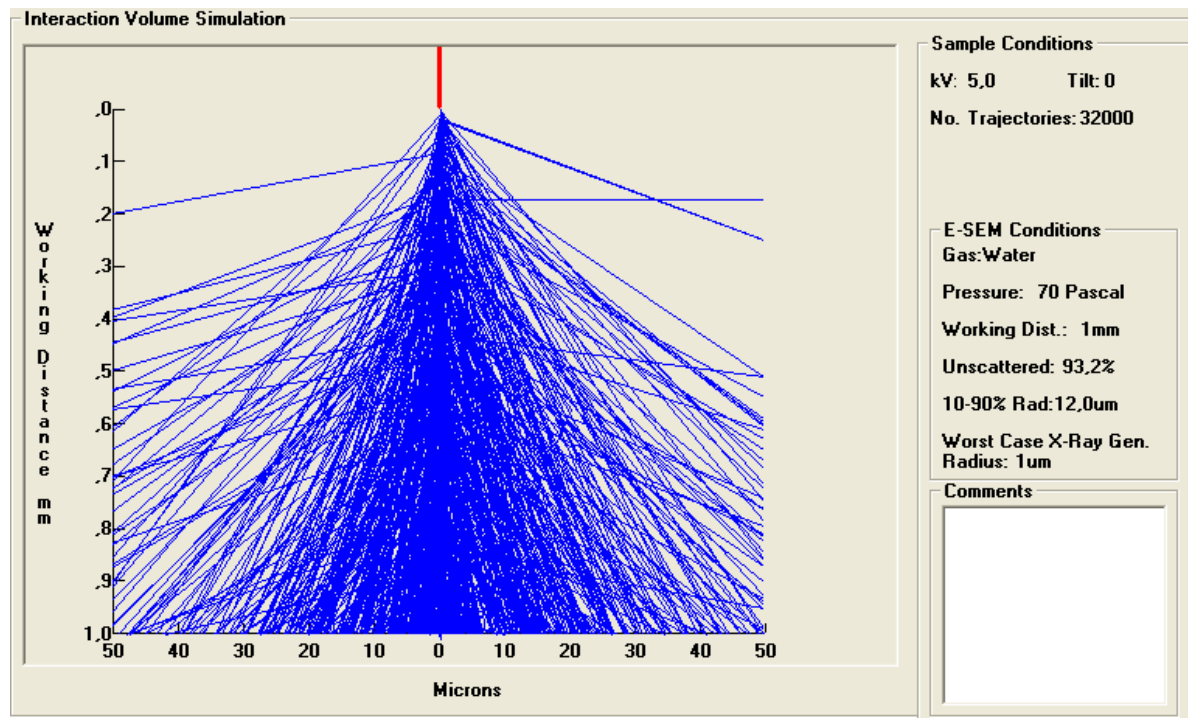

Fig. 7a. Monte Carlo simulation using Electron Flight Simulator of the electron beam scattering under water vapor, $\mathrm{V}=5 \mathrm{kV}, \mathrm{P}=70 \mathrm{~Pa}, \mathrm{GPL}=1 \mathrm{~mm}$.

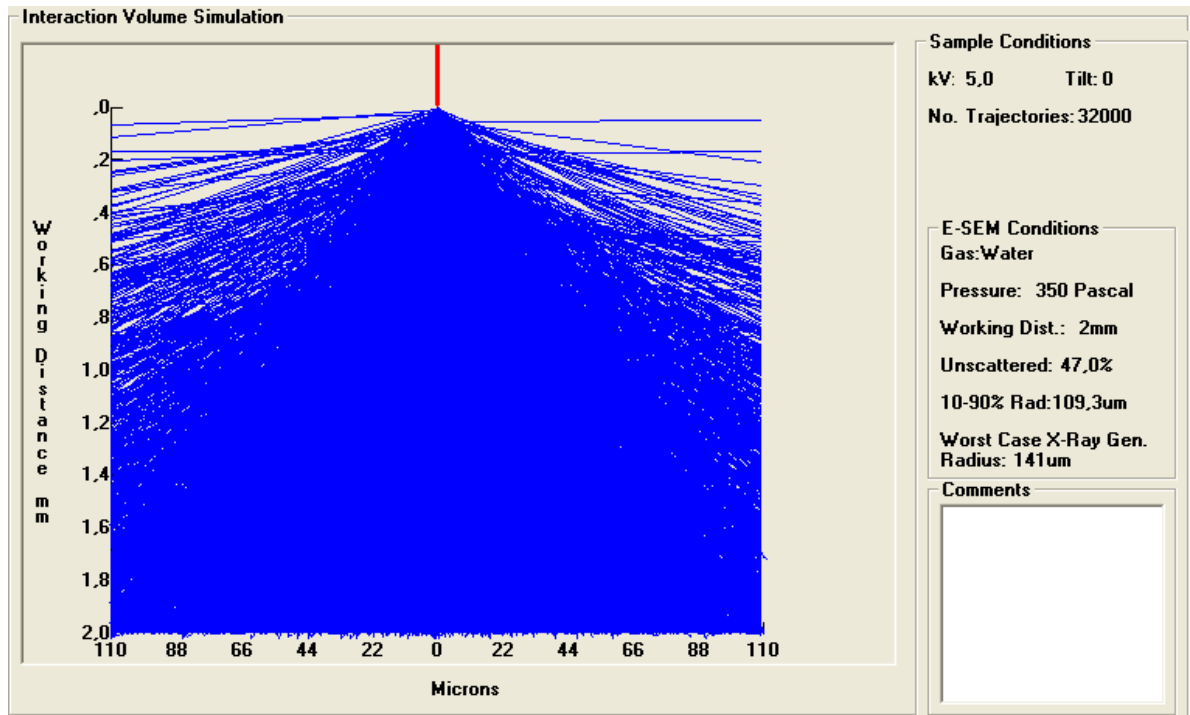

Fig. 7b. Monte Carlo simulation using Electron Flight Simulator of the electron beam scattering under water vapor, $\mathrm{V}=5 \mathrm{kV}, \mathrm{P}=350 \mathrm{~Pa}, \mathrm{GPL}=2 \mathrm{~mm}$.

As given by equation 4 , the value of rs depends on the gas introduced, the incident energy, the pressure, the temperature and the working distance. Indeed, the good way to minimize the beam skirt phenomena is to optimize different parameters used during X-ray microanalysis. With equation 3 this leads to choose a gas with a low average atomic number, 
to increase the incident beam energy, to reduce the pressure and the gas path length, to increase the temperature. Unfortunately, these conditions lead to a significant limitation to use GSEM. For example for ESEM, the standard gas is water vapor and the best results are obtained by helium (ref Khouchaf). Increasing the incident beam leads to a minimization of the beam skirt by decreasing the resolution and degrading the fragile materials.

Based on the conditions and parameters such as the bem energy, the pressure, the gas, the GPL it's not sufficient to define the limit of the use of GSEM. In order to obtain the best results it is also necessary to take into account the value oft he average number of scattering events per electron $\mathrm{m}$. The best results will be obtained with a minimal scattering regime corresponding to $\mathrm{m}<0.05$. This suggests the use a gas with a low average atomic number (Khouchaf et al, 2011).

Unfortunately most new microscopes use gases with a high average atomic number such as $\left(\mathrm{N}_{2}\right.$, air, $\mathrm{H}_{2} \mathrm{O}$ vapor). The improvement of the results can also be reached by increasing the temperature. One way is to use a gas with a low average atomic number such as helium. Figures $(8 \mathrm{a}$ and $8 \mathrm{~b}$ ) below show the electron Flight Simulator spectra obtained under helium environment. The results may be compared to those in figures $6 \mathrm{a}$ and $6 \mathrm{~b}$.

At $\mathrm{P}=70 \mathrm{~Pa}$ and GPL=1mm, $\mathrm{Uns}_{\mathrm{f}}$ and $\mathrm{r}_{\mathrm{s}}$ are close to $99.8 \%$ and $<1 \mu \mathrm{m}$ respectively and at $\mathrm{P}=$ $350 \mathrm{~Pa}$ and GPL $=2 \mathrm{~mm}$, Unsf and $\mathrm{r}_{\mathrm{s}}$ are close to $99.1 \%$ and $<1 \mu \mathrm{m}$ respectively. It is easy to conclude that the quality of the results will be improved.

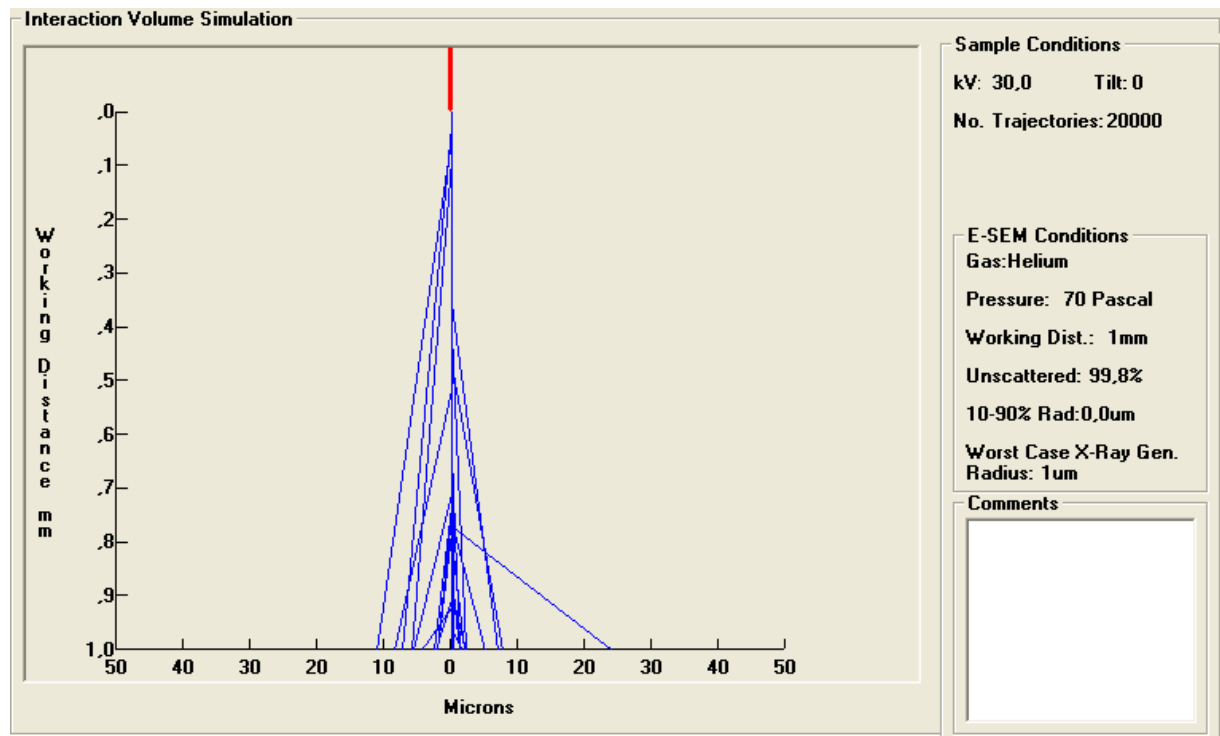

Fig. 8a. Monte Carlo simulation using Electron Flight Simulator of the electron beam scattering under helium, $\mathrm{V}=5 \mathrm{kV}, \mathrm{P}=70 \mathrm{~Pa}, \mathrm{GPL}=1 \mathrm{~mm}$. 


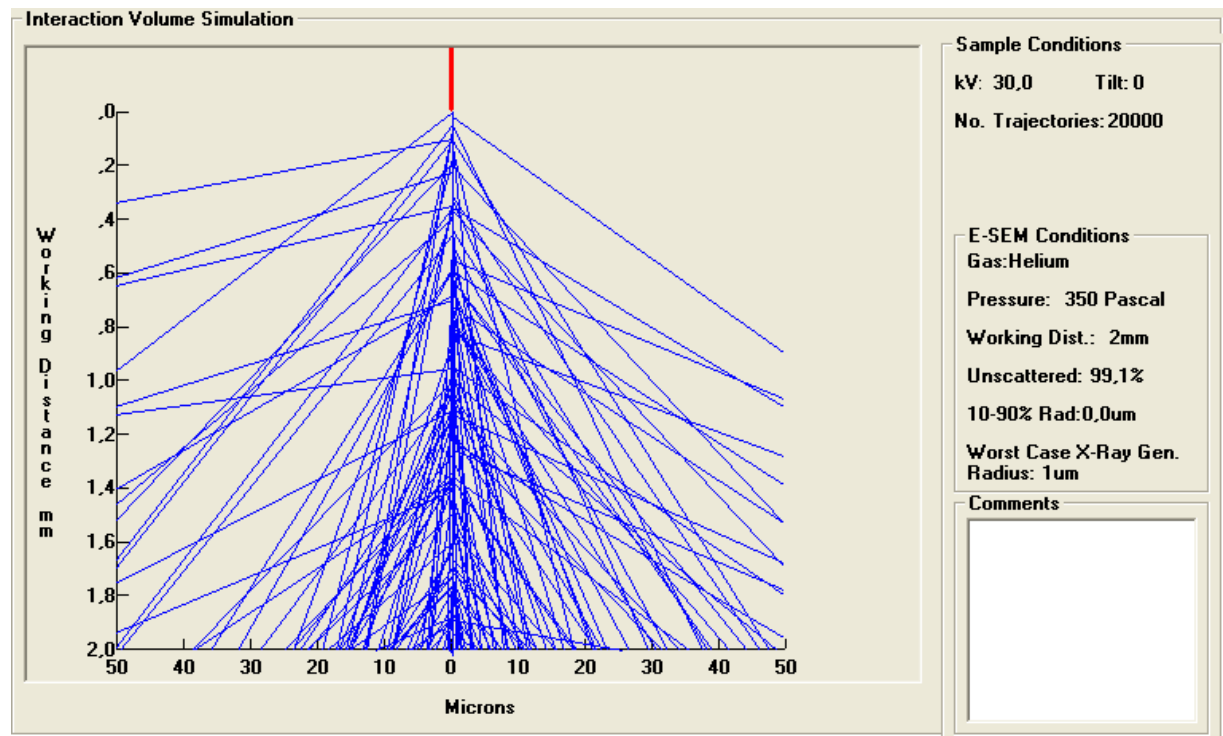

Fig. 8b. Monte Carlo simulation using Electron Flight Simulator of the electron beam scattering under helium, $\mathrm{V}=5 \mathrm{kV}, \mathrm{P}=350 \mathrm{~Pa}, \mathrm{GPL}=2 \mathrm{~mm}$.

\section{Conclusion}

Different types of microscopes with the possibility to introduce different gases inside the sample chamber are now available. Depending on the pressure value in the sample chamber different names are given in the literature such as ESEM, LVSEM, HPSEM, VPSEM, CPSEM. But all these microscopes differ from CSEM by the capability to introduce the gas as environment unlike High vacuum in CSEM. Indeed, all these microscopes work under a gaseous environment and introducing a gaseous detection system in this way may be called gaseous Scanning Electron Microscope (GSEM). In this chapter we demonstrate and confirm the possibility to perform interesting studies with the GSEM if some limitations due to the beam skirt are taken into account. The different correction methods developed are not satisfactory. The good way is to find the best parameters for each experiment in order to obtain the best results based on the average number of collision $\mathrm{m}$. Another way is to develop new microscopes capable of avoiding (isolating) the travel of the electron beam across gaseous environment.

\section{References}

Bilde-Sorensen, JB \& Appel, CC. (1996). Improvements of the spatial resolution of XEDS in the environmental SEM. In EUREM, 11th Euro Congress on EM, Dublin, Ireland, Published by EUREM 96 on CD-ROM

Carlton, PA. (1997). The effect of some instrument operating conditions on the x-ray microanalysis of particles in the environmental scanning electron microscope, Scanning, 19, pp.(85-91) 
Danilatos, G.D. (1980). An atmospheric scanning electron microscope (ASEM). Scanning, 3, pp.(215-217)

Danilatos, G.D. (1988). Foundations of Environmental Scanning Electron Microscopy, Advances in Electronics and Electron Physics. 71. Academic Press, ISBN 0120146711pp. 109250

Danilatos, G.D. (2009). Optimum beam transfer in the environmental scanning electron microscope. Journal of Microscopy, 234, 1, pp.(26-37)

Doehne, E. (1996). A new correction method for energy-dispersive spectroscopy analysis under humid conditions. Scanning, 18, pp.(164-165)

Doehne, E. (1997). A new correction method for high resolution energy dispersive X-ray analyses in the environmental scanning electron microscope. Scanning, 19, pp.(7578)

Fletcher, A.L.; Thiel, B.L.; \& Donald, A.M. (1997). Amplification measurements of potential imaging gases in environmental SEM. J. Phys, D 30, pp.(2249-2257)

Gauvin, R. (1999). Some theoretical considerations on X-ray microanalysis in the environmental or variable pressure scanning electron microscope. Scanning, 21, pp(388-393)

Goldstein, J.; Newbury, D.; Echlin, P.; Joy, C.; Roming, A.D.; Lyman, E.; \& Lifshin, E. (1992). Scanning Electron Microscopy and X-ray Microanalysis, 3rd ed. Plenum Press, ISBN 0306-44175-6, New York, USA

Kadoun, A. ; Belkorissat, R. ; Khelifa, B. ; \& Mathieu, C. (2003). Comparative study of electron beam-gas interaction in an SEM operating at pressures up to 300 Pa.Vacuum, 69, pp.(537- 543)

Khouchaf, L.; Blondiaux, J.; Hedouin, V.; Gosset, D. ; Dürr, J. \& Flipo, R.-M. (2000). La Microscopie Electronique à Balayage Environnementale équipée en Microanalyse $X$ : son utilisation en Pathologie Osseuse Humaine. Perspectives et limites. Journal. Phys. IV, 10, pp.(551-559)

Khouchaf, L. \& Verstraete J. (2002). X-ray microanalysis in the environmental scanning electron microscope (ESEM): Small size particles analysis limits. J. Phys. IV, 12, 6, pp.(341-346)

Khouchaf, L. \& Verstraete, J. (2004). J. Electron scattering by gas in the Environmental Scanning Electron Microscope (ESEM): Effects on the image quality and on the Xray microanalysis. J. Phys IV, 118, pp.(237-243)

Khouchaf, L.; Boinski, F. (2007). Environmental Scanning Electron Microscope study of $\mathrm{SiO}_{2}$ heterogeneous material with helium and water vapor, Vacuum, 81, pp.(599-603)

Khouchaf, L.; Mathieu C. \& Kadoun, A. (2010). Electron microbeam changes under gaseous environment: CP-SEM case and microanalysis limits, Microscopy: Science, Technology, Applications and Education, A. Méndez-Vilas and J. Díaz (Eds.), FORMATEX, ISBN-13: 978-84-614-6190-5, Badajoz, Spain

Khouchaf, L.; Mathieu C. \& Kadoun, A. (2011). Microanalysis results with low Z gas inside Environmental SEM. Vacuum, 86, pp.(62-65)

Le Berre, J.F; Demopoulos, G.P; Gauvin, G. (2007). Skirting: A Limitation for the Performance of X-ray Microanalysis in the Variable Pressure or Environmental Scanning Electron Microscope. Scanning, 29, pp.(114-122)

Mansfield, J.F. (2000). X-ray microanalysis in the environmental SEM. a challenge or a contradiction, Mikrochim Acta,132, pp(137-143) 
Mansour, O.; Aidaoui, K.; Kadoun, A.; Khouchaf, L. \& Mathieu, C. (2010). Monte Carlo simulation of the electron beam scattering under gas mixtures in an HPSEM at low energy. Vacuum, 84, pp.(458463)

Newbury, D. (2002). X-Ray Microanalysis in the Variable Pressure (Environmental) Scanning Electron Microscope. J. Res. Natl. Inst. Stand. Technol.,107, pp.(567-603)

Newbury, D.; Joy, C.; Echlin, P.; Fiori, C. \& Goldstein, J. (1986). Advanced Scanning Electron Microscopy and X-ray Microanalysis, Plenum Press, ISBN 0-306-42140-2, New York, USA

Stokes, D. J.; (2008). Principles and practice of Variable Pressure/Environmental scanning electron microscopy (VP-ESEM), John Wiley \& Sons, Ltd. ISBN: 978-0-470-06540-2, Cornwall, UK

Wight, A. (2001). Experimental data and model simulations of beam spread in the environmental scanning electron microscope. Scanning, 23, pp.(320-327) 


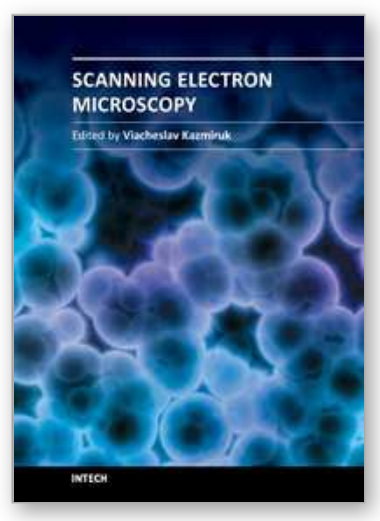

\author{
Scanning Electron Microscopy \\ Edited by Dr. Viacheslav Kazmiruk
}

ISBN 978-953-51-0092-8

Hard cover, 830 pages

Publisher InTech

Published online 09, March, 2012

Published in print edition March, 2012

Today, an individual would be hard-pressed to find any science field that does not employ methods and instruments based on the use of fine focused electron and ion beams. Well instrumented and supplemented with advanced methods and techniques, SEMs provide possibilities not only of surface imaging but quantitative measurement of object topologies, local electrophysical characteristics of semiconductor structures and performing elemental analysis. Moreover, a fine focused e-beam is widely used for the creation of micro and nanostructures. The book's approach covers both theoretical and practical issues related to scanning electron microscopy. The book has 41 chapters, divided into six sections: Instrumentation, Methodology, Biology, Medicine, Material Science, Nanostructured Materials for Electronic Industry, Thin Films, Membranes, Ceramic, Geoscience, and Mineralogy. Each chapter, written by different authors, is a complete work which presupposes that readers have some background knowledge on the subject.

\title{
How to reference
}

In order to correctly reference this scholarly work, feel free to copy and paste the following:

Lahcen Khouchaf (2012). Gaseous Scanning Electron Microscope (GSEM): Applications and Improvement, Scanning Electron Microscopy, Dr. Viacheslav Kazmiruk (Ed.), ISBN: 978-953-51-0092-8, InTech, Available from: http://www.intechopen.com/books/scanning-electron-microscopy/variable-pressure-and-environmentalsem-vp-sem-applications-and-improvement-

\section{INTECH}

open science | open minds

\author{
InTech Europe \\ University Campus STeP Ri \\ Slavka Krautzeka 83/A \\ 51000 Rijeka, Croatia \\ Phone: +385 (51) 770447 \\ Fax: +385 (51) 686166 \\ www.intechopen.com
}

\author{
InTech China \\ Unit 405, Office Block, Hotel Equatorial Shanghai \\ No.65, Yan An Road (West), Shanghai, 200040, China \\ 中国上海市延安西路65号上海国际贵都大饭店办公楼 405 单元 \\ Phone: +86-21-62489820 \\ Fax: $+86-21-62489821$
}


(C) 2012 The Author(s). Licensee IntechOpen. This is an open access article distributed under the terms of the Creative Commons Attribution 3.0 License, which permits unrestricted use, distribution, and reproduction in any medium, provided the original work is properly cited. 